\title{
AUDIT SISTEM INFORMASI MENGGUNAKAN FRAMEWORK COBIT 4.1 SEBAGAI UPAYA EVALUASI PENGOLAHAN DATA PADA SMKK BPK PENABUR BANDAR LAMPUNG
}

\author{
Dedi Darwis ${ }^{1,}$ Dwi Maila Pauristina ${ }^{2}$ \\ Fakultas Teknik dan Ilmu Komputer, Universitas Teknokrat Indonesia \\ Jl. Zaenal Abidin Pagaralam No. 9-11 Kedaton Bandarlampung \\ darwisdedi@ teknokrat.ac.id ${ }^{1}$, dwimailape@gmail.com ${ }^{2}$
}

\begin{abstract}
BPK Penabur SMK Bandar Lampung is one of the schools that has utilized information technology, namely the use of the DAPODIK system. The use of the DAPODIK system at the BPK Penabur Bandar Lampung BPKK is a performance supporter for its users, but this does not guarantee that the BPK Penabur Bandar Lampung SMKK has truly implemented information technology properly. To anticipate the occurrence of unwanted or incompatible data processing according to the data entered, as well as data misuse, fraud in data processing, an information system audit must be carried out. An information system audit was carried out to provide the information needed by the BPK Penabur Bandar Lampung VOCATIONAL SCHOOL in achieving its objectives. Data collection is done by distributing questionnaires, interviews, documentation and direct observation. The results of the data collection are used to find out the weaknesses of the system at the BPKK Penabur Bandar Lampung Vocational School. This information system audit uses the COBIT 4.1 framework as a research method because the other models do not have as broad a scope as the four COBIT 4.1 domains, the domain used in this study is the DS (Delivery and Support) and ME (Monitor and Evaluate) domains consisting of 10 processes which aims to find out to what extent SMK Bandar Penabur Bandar Lampung has implemented information technology well. The results of the evaluation of the audit of data processing information systems at BPK Penabur Bandar Lampung BPK shows that the problem found in the DS (Delivery and Support) is DS12 (Managing the Physical Environment). has good physical access security measures and there is no protection yet against the physical security of the DAPODIK system.
\end{abstract}

Keyword : COBIT 4.1, Information Systems Audit.

\section{Abstrak}

SMKK BPK Penabur Bandar Lampung merupakan salah satu sekolah yang telah memanfaatkan teknologi informasi yaitu penggunaan sistem DAPODIK. Penggunaan sistem DAPODIK pada SMKK BPK Penabur Bandar Lampung merupakan pendukung kinerja bagi penggunanya, namun hal tersebut belum menjamin bahwa SMKK BPK Penabur Bandar Lampung tersebut sudah betul-betul menerapkan teknologi informasi dengan baik. Untuk mengantisipasi terjadinya pengolahan data yang tidak diinginkan atau tidak sesuai dengan data yang diinputkan, serta adanya penyalahgunaan data, kecurangan dalam pengolahan data, maka harus dilakukan audit sistem informasi. Audit sistem informasi dilakukan untuk memberikan informasi yang diperlukan oleh SMKK BPK Penabur Bandar Lampung dalam mencapai tujuannya. Pengumpulan data dilakukan dengan cara menyebarkan kuesioner, wawancara, dokumentasi dan observasi secara langsung. Hasil pengumpulan data digunakan untuk mengetahui kelemahan-kelemahan sistem pada SMKK BPK Penabur Bandar Lampung. Audit sistem informasi ini menggunakan framework COBIT 4.1 sebagai metode penelitian karena model-model lain tidak mempunyai cakupan seluas keempat domain COBIT 4.1, domain yang digunakan pada penelitian ini adalah domain DS (Delivery and Support) dan ME (Monitor and Evaluate) terdiri dari 10 proses yang bertujuan mengetahui sejauh mana SMKK BPK Penabur Bandar Lampung telah menerapkan teknologi informasi dengan baik. Hasil evaluasi audit sistem informasi pengolahan data pada SMKK BPK Penabur Bandar Lampung menunjukkan temuan masalah pada DS (Delivery and Support) adalah DS12 (Mengelola Lingkungan Fisik) masalah pada bagian ini adalah ketidaksesuaian terhadap data yang diinputkan dengan output yang dibutuhkan oleh pengguna dan sistem DAPODIK belum memiliki tindakan keamanan akses fisik yang baik serta belum adanya perlindungan terhadap keamanan fisik sistem DAPODIK.

Kata Kunci : COBIT 4.1, Audit Sistem Informasi.

\section{PENDAHULUAN}

\subsection{Latar Belakang}

Dampak dari perkembangan teknologi dirasakan pada bidang pendidikan. Teknologi Informasi (TI) sebagai sarana untuk menunjang penyampaian data/informasi yang digunakan pihak manajemen organisasi sebagai acuan dalam pengambilan keputusan. Untuk memastikan bahwa TI telah dilaksanakan sesuai dengan tujuan organisasi, maka perlu dilakukan audit. Audit Sistem Informasi dilakukan secara periodik untuk menjamin keberlanjutan operasional IT yang digunakan oleh organisasi serta untuk 
menilai kesesuaian antara perencanaan dan implementasi sistem informasi. Audit Sistem Informasi digunakan untuk mengukur seberapa jauh sistem yang sudah menjadi ketentuan dalam organisasi tersebut telah terlaksana dengan baik dan memungkinkan untuk dipakai sebagai alat bantu pemeriksaan tentang adanya kemungkinan penyimpangan di dalam sistem [1],[2].

DAPODIK (Data Pokok Pendidikan) merupakan salah satu pemanfaatan teknologi informasi dalam bidang pendidikan, DAPODIK adalah sistem pengolah data pokok pendidikan seperti data identitas sekolah, data lokasi sekolah, data pelengkap sekolah, data kontak sekolah, data periodik, data prasarana, data sarana, data rombongan belajar (rombel), data pendidik dan tenaga kependidikan (PTK) serta data peserta didik yang dilakukan secara online. Data yang masuk akan dimanfaatkan dalam berbagai kebijakan pendidikan seperti Bantuan Operasional Sekolah (BOS), Bantuan Sosial (Bansos), Tunjangan, UN dan lain-lain.

Sekolah Menengah Kejuruan Kristen BPK Penabur Bandar Lampung merupakan salah satu sekolah yang telah memanfaatkan sistem DAPODIK. Penggunaan sistem DAPODIK pada SMKK BPK Penabur Bandar Lampung merupakan pendukung kinerja bagi penggunanya, namun hal tersebut belum menjamin bahwa SMKK BPK Penabur Bandar Lampung tersebut telah betul-betul menerapkan teknologi informasinya dengan baik. Sistem DAPODIK yang telah diterapkan pada SMKK BPK Penabur Bandar Lampung belum di audit apakah telah mencapai visi dan misi sekolah, untuk itu diperlukan audit sistem informasi untuk mengendalikan dan memastikan bahwa sistem DAPODIK sudah sesuai dengan tujuan organisasi dan untuk mengantisipasi terjadinya pengolahan data yang tidak diinginkan atau tidak sesuai dengan data yang diinputkan, serta adanya penyalahgunaan data, kecurangan dalam pengolahan data, maka harus dilakukan audit sistem informasi. Audit sistem informasi ini menggunakan framework COBIT 4.1 (Control Objectives for Information and Related Technology).

COBIT 4.1 merupakan metode audit sistem informasi yang digunakan oleh IT Governance. COBIT 4.1 berfungsi mempertemukan semua kebutuhan kontrol dan isu-isu teknik, selain itu COBIT juga dirancang menjadi alat bantu untuk memecahkan permasalahan dengan cara mengelola risiko serta hubungan antar sumber daya informasi. Kerangka kerja COBIT membagi proses teknologi informasi menjadi 4 domain, yaitu Planning and Organization (PO), Acquisition and Implementation (AI), Delivery and Support (DS) serta Monitor and Evaluate (ME) dengan keseluruhan 34 proses yang ada di dalamnya. Standar COBIT 4.1 digunakan karena memiliki keluasan cakupan pengelolaan dan kedetilan proses-prosesnya dibandingkan dengan standar-standar lainnya $[3],[4],[5],[6]$.

\subsection{Rumusan Masalah}

Berdasarkan latar belakang maka rumusan masalah dalam penelitian ini adalah bagaimana mengaudit sistem informasi pengolahan data menggunakan framework COBIT 4.1 dengan domain Delivery and Support (DS) dan
Monitor and Evaluate (ME) pada SMKK BPK Penabur Bandar Lampung? dan bagaimana hasil rekomendasi terhadap evaluasi pengolahan data menggunakan framework COBIT 4.1 dengan domain Delivery and Support (DS) dan Monitor and Evaluate (ME) pada SMKK BPK Penabur Bandar Lampung

\subsection{Batasan Masalah}

Batasan masalah dari penelitian ini hanya membahas :

1. Informasi dan data yang digunakan untuk proses audit sistem informasi hanya pada sistem informasi DAPODIK yang ada pada SMKK BPK Penabur Bandar Lampung.

2. Domain yang digunakan untuk proses audit yaitu Delivery and Support (DS) dan Monitor and Evaluate (ME).

3. Proses dari masing-masing domain yang digunakan yaitu DS5 (Memastikan Keamanan Sistem), DS7 (Mendidik dan Melatih Pengguna), DS10 (Mengelola Permasalahan), DS11 (Mengelola Data), DS12 (Mengelola Lingkungan Fisik), DS13 (Mengelola Operasi), ME1 (Pemantauan dan Evaluasi Kinerja TI), ME2 (Memantau dan Mengevaluasi Pengendalian Internal), ME3 (Memastikan Pemenuhan Persyaratan Eksternal), ME4 (Menyediakan Tata Kelola TI).

4. Metode penilaian dan pengukuran tingkat kematangan yang diambil berdasarkan Maturity Level.

\subsection{Tujuan Penelitian}

Tujuan dari penelitian ini adalah melakukan evaluasi terhadap Sistem Informasi pengolahan data DAPODIK pada SMKK BPK Penabur Bandar Lampung dan pembuatan rekomendasi untuk mencapai level yang lebih baik dari hasil yang telah di audit.

\subsection{Manfaat Penelitian}

Manfaat dari penelitian ini adalah memberikan pengetahuan tentang menghitung Maturity Level proses sebuah sistem serta memberikan pengetahuan tahap-tahap melakukan audit sistem informasi.

\section{LANDASAN TEORI}

\subsection{Pengertian Audit Sistem Informasi}

"evaluasi yang bersifat independen atau kebijakan, prosedur, standar pengukuran dan praktik untuk menjaga/mencegah informasi yang bersifat elektronik dari kehilangan, kerusakan penelusuran yang tidak disengaja dan sebagainya" [7],[8].

\subsection{Jenis-Jenis Audit}

a. Financial Audit, memeriksa keterdalaman dan integritas dari transaksi-transaksi keuangan, catatan akuntansi dan laporan keuangan.

b. Internal Control Audit, memeriksa kebijakan posedur pengendalian internal serta efektifitas dalam pengamanan aset, audit tersebut biasanya mengevakuasi input dan output sistem, pengendalian pemrosesan, rencana backup dan pemulihan keamanan sistem serta fasilitas sistem. 
c. Operational Audit, berkaitan dengan pengunaan secara ekonomis dan efisien atas sumber daya pencapaian tujuan serta sasaran yang diterapkan.

d. Compiance Audit, menentukan apakah entitas mematuhi hukum, peraturan, kebijakan, dan prosedur yang berlaku. Audit ini sering menghasilkan rekomendasi untuk meningkatkan proses dan pengendalian yang digunakan untuk memastikan kepatuhan terhadap regulasi.

e. Investigative Audit, menguji kejadian-kejadian dari penipuan yang mungkin terjadi, penggunaan aset yang tidak tepat, pemborosan dan penyalahgunaan atau aktivitas tata kelola yag buruk [8].

\subsection{Tujuan Audit Sistem Informasi}

"untuk memeriksa dan mengevaluasi pengendalian internal yang melindungi sistem" [8].

Ketika melakukan sebuah audit sistem informasi para auditor seharusnya memastikan bahwa enam tujuan berikut telah tercapai yaitu :

a. Ketentutan keamanan untuk melindungi peralatan komputer, program, komunikasi dan data-data dari akses, modifikasi, atau penghancuan yang tidak di otorisasi.

b. Pengembangan dan akuisisi program dilakukan sesuai dengan otorisasi umum dan spesifikasi manajemen.

c. Modifikasi program mendpatkan otorisasi dan perssetujuan manajemen.

d. Pemrosesan transaksi, file, laporan, catatan, dan catatan komputer lain nya tepat dan lengkap.

e. Data sumber yang tidak tepat atau tidak diotorisasi dengan benar diidentifikasi dan ditangani berdasarkan kebijakan manajerial yang telah ditentukan.

f. File-file data komputer tepat, lengkap, dan rahasia.

\subsection{Pengertian Framework COBIT 4.1}

Control Objectives for Information and Related Technology (COBIT), pertama kali diterbitkan pada April 1996. COBIT adalah framework pertama yang diakui secara internasional untuk IT Governance and Control. Versi COBIT 4.1 dirilis pada tahun 2007. COBIT dikembangkan oleh IT Governance Institute (ITGI) dengan bekerjasama dengan ahli dari berbagai bidang industri, akademisi, pemerintah, serta keamanan IT dan kontrol. Dalam penelitiannya dilakukan secara mendalam dengan cara mempelajari dari berbagai sumber untuk bekerja sama untuk menghasilkan ide-ide terbaik untuk membuat standar teknis dan professional [10].

Kerangka kerja COBIT 4.1 membagi proses teknologi informasi menjadi 4 domain, yaitu Plan and Organise (PO), Acquire and Implement (AI), Deliver and Support (DS), serta Monitor and Evaluate (ME) dengan keseluruhan 34 proses yang ada di dalamnya [10].

COBIT 4.1 dipilih karena memiliki cakupan yang luas untuk proses pengelolaan teknologi informasi, dan kedetilan proses-prosesnya.

\subsection{Domain Framework COBIT 4.1}

Kerangka kerja COBIT membagi proses teknologi informasi menjadi 4 domain, yaitu Planning and Organization (PO), Acquisition and Implementation (AI),
Delivery and Support (DS) serta Monitor and Evaluate (ME) dengan keseluruhan 34 proses yang ada di dalamnya.

\section{METODE PENELITIAN}

\subsection{Tahapan Penelitian Audit}

Tahapan Penelitian Audit Sistem Informasi menggunakan Framework Cobit 4.1 sebagai evaluasi pengolahan data pada SMK BPK Penabur Bandar Lampung dapat dilihat pada gambar 3.2 berikut ini :

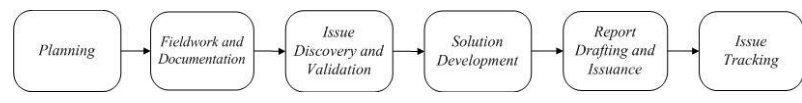

Gambar 1. Tahapan Penelitian

\subsection{Pengumpulan Data}

Pada tahap ini penulis melakukan pengumpulan data yang dibutuhkan untuk penelitian. Pengumpulan data berupa :

a. Wawancara

Pengumpulan data melalui wawancara dilakukan dalam suasana tidak formal. Penulis melakukan wawancara terhadap manajemen dan pengguna teknologi informasi khusus pada Bagian Administrasi SMKK BPK Penabur Bandar Lampung. Wawancara dilakukan dengan metode interview dimana penulis mengajukan pertanyaan dan narasumber memberikan jawaban. Jawaban dari narasumber tidak dibatasi hanya pada list soal untuk menghindari jawaban yang kaku, pertanyaan disampaikan secara random tapi mencakup keseluruhhan data yang dibutuhkan.

b. Observasi

Pada tahap observasi, penulis melakukan pengamatan secara langsung terhadap proses / kegiatan yang sedang berjalan pada SMKK BPK Penabur Bandar Lampung. Pengamatan dilakukan sesuai dengan penelitian yaitu di bagian administrasi SMKK BPK Penabur Bandar Lampung.

c. Kuesioner

Kuesioner dalam penelitian ini dirancang untuk mengetahui tingkat kematangan pengelolaan teknologi informasi yang telah digunakan oleh SMKK BPK Penabur Bandar Lampung dengan melihat tanggapan pengguna dan pembuatan keputusan dalam menjalakan teknologi dalam Sekolah tersebut. Penyebaran kuesioner dilakukan dengan melibatkan pegawai-pegawai SMKK BPK Penabur Bandar Lampung.

Kuesioner berisi pertanyaan-pertanyaan sesuai pada domain Delivery and Support (DS) dan Monitor and Evaluate (ME) dengan total 10 proses yang dipakai, kemudian dari masing-masing proses diuraikan menjadi aktivitas-aktivitas. Masing-masing penilaian memiliki tingkat nilai yang berbobot antara 0 sampai dengan 5 sesuai dengan dasar yang terdapat pada framework COBIT.

\section{d. Tinjauan Pustaka}

Tinjauan pustaka dilakukan oleh penulis dengan mempelajari mengenai penelitian-penelitian terdahulu 
yang berkaitan dengan penelitian. Penelitian terdahulu berupa jurnal penelitian.

e. Dokumentasi

Pada tahap dokumentasi, penulis melakukan pengumpulan dokumen-dokumen yang berkaitan dengan penelitian, dokumen-dokumen tersebut dapat berupa laporan atau sebagainya.

\subsection{Analisis Data}

Pada tahap ini penulis melakukan uji validitas selanjutnya dilakukan perhitungan Maturity Level untuk mengukur level kematangan sistem berdasarkan data kuesioner yang sudah di uji validitas. Setelah itu dilakukan analisis kemudian diberikan rekomendasi perbaikan. Rumus yang digunakan untuk menghitung Indeks Maturity Level yaitu :

$$
\text { Mean }(\text { or } \bar{X})^{*}=\frac{\sum X_{i}}{n}=\frac{X_{1}+X_{2}+\ldots+X_{n}}{n}
$$

Keterangan :

$$
\begin{aligned}
& \overline{\mathcal{X}}: \text { Mean (rata-rata) } \\
& \sum_{\mathrm{X}}: \text { Jumlah } \\
& \mathrm{n}: \text { Jumlai X, } \mathrm{i}=1,2,3, \ldots n \\
&
\end{aligned}
$$

\section{HASIL DAN PEMBAHASAN}

\subsection{Identifikasi Enterprise Goals}

Pada tahap ini penulis mengelompokkan enterprise goals dari SMKK BPK Penabur Bandar Lampung, dengan enterprise goals yang ada pada COBIT 4.1 dengan cara melihat tujuan penelitian yaitu mengolah data maka penulis mengkategorikan tujuan tersebut kedalam tujuan perusahaan (enterprise goals) yang terdapat pada COBIT 4.1 pada bagian Obtain reliable and useful information for strategic decision making.

Enterprise goals dari SMKK BPK Penabur Bandarlampung termasuk kedalam kategori Obtain reliable and usefull information for strategic decision making karena SMKK BPK Penabur Bandarlampung mengharapkan peningkatan dalam hal pengolahan data sistem DAPODIK. Penentuan enterprise goals pada SMKK BPK Penabur berdasarkan hasil wawancara dengan stakeholder yaitu Ketua Yayasan BPK Penabur Bandar Lampung.

\subsection{Identifikasi IT Goals}

Pada tahap ini penulis melakukan pemilihan IT Goals, berdasarkan tabel enterprise goals. Ada lima IT Goals (2,4,12,20 dan 26) yang memiliki hubungan dengan Obtain reliable and usefull information for strategic decision making.

Dengan mengetahui IT Goals yang berkaitan dengan enterprise goals, penulis dapat melanjutkan ketahap selanjutnya yaitu penentuan Domain COBIT 4.1 yang akan digunakan dan yang disesuaikan dengan SMKK BPK Penabur Bandar Lampung.

\subsection{Identifikasi Domain COBIT 4.1}

Pada tahap ini, penulis menetapkan domain teknologi informasi yang sesuai dengan standar COBIT 4.1 yang telah diolah sesuai dengan studi kasus, maka domain teknologi informasi pada SMKK BPK Penabur Bandar Lampung dapat dilihat pada tabel 1 berikut ini :

Tabel 1. Domain teknologi informasi pada SMKK BPK Penabur

\begin{tabular}{c} 
Domain COBIT 4.1 \\
\hline Delivery and Support (DS) \\
Monitor and Evaluate (ME)
\end{tabular}

\subsection{Identifikasi Proses COBIT 4.1}

Pada tahap ini, penulis memilih proses berdasarkan domain yang telah dipilih pada tahap sebelumnya sesuai dengan standar COBIT 4.1 dan disesuaikan dengan yang ada pada SMKK BPK Penabur Bandar Lampung, maka Proses dari Domain teknologi informasi pada SMKK BPK Penabur Bandar Lampung dapat dilihat pada tabel 2 berikut ini :

Tabel 2. Proses dari Domain teknologi informasi pada SMKK BPK Penabur

Domain Delivery and Support (DS)

\begin{tabular}{ll}
\hline Proses & \multicolumn{1}{c}{ Descript } \\
\hline DS5 & Ensure Systems Security \\
\hline DS7 & Educate and Train Users \\
\hline DS10 & Manage Problems \\
\hline DS11 & Manage Data \\
\hline DS12 & Manage The Physical Environment \\
\hline DS13 & Manage Operations \\
\hline
\end{tabular}

Domain Monitor and Evaluate (ME)

\begin{tabular}{ll}
\hline Proses & \multicolumn{1}{c}{ Descript } \\
\hline ME1 & Monitor and Evaluate IT Performance \\
\hline ME2 & Monitor and Evaluate Internal Control \\
\hline ME3 & $\begin{array}{l}\text { Ensure Compliance With External } \\
\text { Requirements }\end{array}$ \\
\hline ME4 & Provide IT Governance
\end{tabular}

\subsection{Identifikasi Control Objectives (Aktivitas) COBIT 4.1}

Pada tahap ini penulis membagi proses-proses ke dalam aktivitas-aktivitas yang berfungsi sebagai alat control objectives pada penelitian ini. Adapun aktivitasaktivitas dari setiap proses dapat dilihat pada tabel 3 berikut ini :

Tabel 3. IT Control Objectives (Aktivitas) pada SMKK BPK Penabur

\section{Delivery and Support (DS)}

\begin{tabular}{ll}
\hline \multicolumn{2}{l}{ DS5 Ensure Systems Security } \\
\hline DS5.1 & Management of IT Security \\
\hline DS5.5 & $\begin{array}{l}\text { Security Testing, Surveillance and } \\
\text { Monitoring }\end{array}$
\end{tabular}


DS5.11 Exchange of Sensitive Data

\begin{tabular}{ll}
\hline DS7 Educate and Train Users \\
\hline DS7.1 & $\begin{array}{l}\text { Identification of Education and Training } \\
\text { Needs }\end{array}$ \\
\hline DS7.2 & Delivery of Training and Education \\
\hline DS10 Manage Problems \\
\hline DS10.1 & $\begin{array}{l}\text { Identification and Classification of } \\
\text { Problems }\end{array}$ \\
\hline DS10.2 & Problem Tracking and Resolution \\
\hline DS10.4 & $\begin{array}{l}\text { Integration of Configuration, Incident } \\
\text { and Problem Management }\end{array}$
\end{tabular}

4.6. Perhitungan Tingkat Kematangan, Kesenjangan (GAP) \& Rekomendasi

Hasil perhitungan nilai kematangan dari domain Delivery and Support (DS) dan domain Monitor and Evaluate (ME) dilihat pada tabel 4.4 berikut ini :

Tabel 4 Hasil Perhitungan Nilai Kematangan Domain DS dan ME

\begin{tabular}{|c|c|c|c|}
\hline & $\begin{array}{c}\text { Keterangan } \\
\text { Proses }\end{array}$ & Nilai & $\begin{array}{c}\text { Level } \\
\text { Kematangan }\end{array}$ \\
\hline DS5 & $\begin{array}{l}\text { Memastikan } \\
\text { Keamanan } \\
\text { Sistem }\end{array}$ & 2,3 & $\begin{array}{l}\text { Repeatable But } \\
\text { Intuitive }\end{array}$ \\
\hline DS7 & $\begin{array}{l}\text { Mendidik dan } \\
\text { Melatih } \\
\text { Pengguna }\end{array}$ & 2,2 & $\begin{array}{l}\text { Repeatable But } \\
\text { Intuitive }\end{array}$ \\
\hline DS10 & $\begin{array}{l}\text { Mengelola } \\
\text { Permasalahan }\end{array}$ & 2,2 & $\begin{array}{c}\text { Repeatable But } \\
\text { Intuitive }\end{array}$ \\
\hline DS11 & $\begin{array}{l}\text { Mengelola } \\
\text { Data }\end{array}$ & 2,4 & $\begin{array}{l}\text { Repeatable But } \\
\text { Intuitive }\end{array}$ \\
\hline $\mathrm{DS} 12$ & $\begin{array}{l}\text { Mengelola } \\
\text { Lingkungan } \\
\text { Fisik }\end{array}$ & 2,0 & $\begin{array}{l}\text { Repeatable But } \\
\text { Intuitive }\end{array}$ \\
\hline DS13 & $\begin{array}{l}\text { Mengelola } \\
\text { Operasi }\end{array}$ & 2,4 & $\begin{array}{l}\text { Repeatable But } \\
\text { Intuitive }\end{array}$ \\
\hline ME1 & $\begin{array}{l}\text { Pemantauan } \\
\text { dan Evaluasi } \\
\text { Kinerja } \\
\text { Teknologi } \\
\text { Informasi }\end{array}$ & 2,2 & $\begin{array}{l}\text { Repeatable But } \\
\text { Intuitive }\end{array}$ \\
\hline ME2 & $\begin{array}{l}\text { Memantau } \\
\text { dan } \\
\text { Mengevaluasi } \\
\text { Pengendalian } \\
\text { Internal }\end{array}$ & 2,3 & $\begin{array}{l}\text { Repeatable But } \\
\text { Intuitive }\end{array}$ \\
\hline ME3 & $\begin{array}{l}\text { Memastikan } \\
\text { Pemenuhan } \\
\text { Persyaratan } \\
\text { Eksternal }\end{array}$ & 2,2 & $\begin{array}{l}\text { Repeatable But } \\
\text { Intuitive }\end{array}$ \\
\hline ME4 & $\begin{array}{l}\text { Menyediakan } \\
\text { Tata Kelola } \\
\text { Teknologi } \\
\text { Informasi }\end{array}$ & 2,4 & $\begin{array}{l}\text { Repeatable But } \\
\text { Intuitive }\end{array}$ \\
\hline & Rata-rata & 2,2 & $\begin{array}{c}\text { Repeatable But } \\
\text { Intuitive }\end{array}$ \\
\hline
\end{tabular}

Pada tabel hasil perhitungan nilai kematangan Domain DS dan ME diatas dapat dijelaskan bahwa rata-rata dari proses DS5, DS7, DS10, DS11, DS12, DS13, ME1, ME2, ME3 dan ME4 menghasilkan nilai tingkat kematangan 2,2. Dari nilai kematangan ini dapat ditarik kesimpulan bahwa pengelolaan teknologi informasi pada SMKK BPK Penabur Bandar Lampung berada pada level Repetable But Intuitive artinya pada level ini, masih dibutuhkan banyak perbaikan. Kesenjangan pada Domain DS dan ME dapat dilihat pada tabel 5 berikut ini :

Tabel 5. Analisis Kesenjangan (GAP) Domain DS dan ME

Tingkat Kematangan

\begin{tabular}{cccc}
\multirow{2}{*}{ Proses } & \multicolumn{3}{c}{ Tingkat Kematangan } \\
\cline { 2 - 4 } & Saat Ini & Diharapkan & GAP \\
\hline DS5 & 2,3 & 3,0 & 0,7 \\
\hline DS7 & 2,2 & 3,0 & 0,8 \\
\hline DS10 & 2,2 & 3,0 & 0,8 \\
\hline DS11 & 2,4 & 3,0 & 0,6 \\
\hline DS12 & 2,0 & 3,0 & 1,0 \\
\hline DS13 & 2,4 & 3,0 & 0,6 \\
\hline ME1 & 2,2 & 3,0 & 0,8 \\
\hline ME2 & 2,3 & 3,0 & 0,7 \\
\hline ME3 & 2,2 & 3,0 & 0,8 \\
\hline ME4 & 2,4 & 3,0 & 0,6 \\
\hline & GAP & & $\mathbf{0 , 7}$
\end{tabular}

Didapat Kesenjangan 0,7 pada Domain DS dan ME antara nilai tingkat kematangan saat ini dengan nilai tingkat kematangan yang diharapkan. Walaupun GAP terbilang kecil tetapi dibutuhkan penyesuaian masingmasing proses karena 0,7 merupakan nilai rata-rata perproses, maka penulis akan tetap memberikan rekomendasi pada masing-masing proses sehingga perbaikan lebih fokus pada bagian proses yang lemah. Rekomendasi secara umum untuk audit sistem informasi pengolahan data pada SMKK BPK Penabur Bandar Lampung pada domain DS ini adalah melakukan tindakan keamanan akses fisik secara maksimal serta melakukan perlindungan terhadap keamanan fisik sistem DAPODIK.

\section{KESIMPULAN}

\subsection{Simpulan}

Berdasarkan hasil dari penelitian maka dapat di hasilkan simpulan sebagai berikut:

1. Hasil pengolahan kuesioner mendapati nilai rata-rata untuk domain DS dan ME adalah 2,2 dari rentang nilai 0 sampai 5. Artinya SMKK BPK Penabur Bandar Lampung telah melakukan proses pengolahan data namun belum baku atau belum mengikuti standar yang ada.

2. Hasil penelitian menemukan kelemahan terdapat pada proses DS12 karena hanya mampu memperoleh nilai rata-rata 2,0 artinya masih pada level Repeatable But Intuitive. Beberapa kelemahan lain adalah belum memiliki prosedur yang baku dalam proses pengolahan data dan informasi, sehingga perlunya rekomendasi untuk mencapai tujuan yang diharapkan. 


\subsection{Saran}

Berdasarkan simpulan dari hasil penelitian yang telah diuraikan, maka saran yang dapat diberikan untuk pengembangan lebih lanjut dari pengolahan data sistem DAPODIK pada SMKK BPK Penabur Bandar Lampung adalah sebagai berikut :

1. Audit sistem informasi pengolahan data pada SMKK BPK Penabur Bandar Lampung masa mendatang dapat menggunakan framework COBIT 5 dan menambahkan domain dalam proses audit sistem informasi.

2. Audit sistem informasi pengolahan data pada SMKK BPK Penabur Bandar Lampung masa mendatang memiliki nilai target maturity sebesar 4 dengan level tingkat kematangan Managed and Measureable.

\section{DAFTAR PUSTAKA}

[1] Maniah, Krisdanto Suhendro. "Usulan Model Audit Sistem Informasi (Studi Kasus : Sistem Informasi Perawatan Pesawat Terbang)”. Institut Teknologi Bandung. Yogyakarta, Juni 2005.

[2] Suryono, Ryan Randi., Darwis, Dedi., Gunawan, Surya Indra., "Audit Tata Kelola Teknologi Informasi Menggunakan Framework Cobit 5 (Studi Kasus: Balai Besar Perikanan Budidaya Laut Lampung)". Jurnal Teknoinfo, Vol.12.No.1. hal 16-22, 2018.

[3] Biilmilah, Rayin., Darwis, Dedi., "Audit Kinerja Sistem Informasi Penelusuran Perkara pada Pengadilan Agama Tanjung Karang Kelas IA
Bandarlampung”, Jurnal Tekno Kompak. Vol 11. No.1, hal 18-23, 2017

[4] Rahmaani, Amalia Ratna. “Audit Sistem Informasi Akademik UIN Sunan Kalijaga Yogyakarta Menggunakan COBIT Framework Pada Domain Delivery and Support”. Universitas Islam Negeri Sunan Kalijaga. Yogyakarta, 27 Januari 2014.

[5] Hakim, Ummy Pemata., Darwis, Dedi., "Audit Tata Kelola Teknologi Informasi (Emis) Menggunakan Framework Cobit 5 PT TDM Bandarlampung", Jurnal Teknoinfo, Vol.10, No.1, hal 14-19, 2016

[6] Syaroh, Siti, Didit N Utama, Ellensyah Kurniawan. "Audit Sistem Informasi Call Center Pada PT Arga Bangun Bangsa (ESQ LEAERSHIP CENTER) Dengan Menggunakan Framework COBIT”. Univesitas Islam Negeri Syarif Hidayatullah Jakarta. 2011.

[7] Darwis, Dedi., “Audit Tata Kelola Teknologi Informasi Menggunakan Framework COBIT 4.1 sebagai Upaya Peningkatan Keamanan Data pada Dinas Pendidikan dan Kebudayaan Kabupaten Pesawaran”, Jurnal Sistem Informasi dan Telematika, Vol.7, No.2. 2016

[8] Romney, Marshall B., Paul John Steinbart, 2014. Sistem Informasi Akuntansi. Jakarta: Salemba Empat.

[9] Schiller Mike, Chris Davis. 2011. IT Auditing Using Controls To Protect Information Assets. New York : Mc Graw Hill. 